\title{
Yunus: Miskin Visi dan Tidak Misioner?
}

\author{
Seri Damarwanti \\ Sekolah Tinggi Teologi Nazarene Indonesia, Yogyakarta \\ antikmm@yahoo.co.id \\ Sukirdi \\ Sekolah Tinggi Teologi Nazarene Indonesia, Yogyakarta \\ kirdiyohanes@yahoo.co.id
}

\begin{abstract}
Jonah was not the ideal model, chosen to learn how Christian missionaries should be. The contrary response to the call to be a servant of God becomes an interesting study to find out the background that shapes and pushes his attitude. The principles described in this paper lead to a paradoxical condition between missionary idealism and conditions in the field. Through the principles of hermeneutics, especially literary analysis, background analysis, context analysis and theology, its tried to be used to find answer the problems in Jonah's attitude which is contrary to his responsibility as the Prophet of God. The final purpose of this paper is the strengthening of the existence of God as God who provides opportunities for repentant humans, which is manifested in forgiveness, acceptance, cancellation of punishment, and restoration of relations with humans. The practical principles drawn from the discussion become the standard for how Christians should respond through submission to God's authority.
\end{abstract}

Keywords: Jonah; mission; missionary; love; punishment; Nineveh.

\begin{abstract}
Abstrak
Yunus adalah bukan model ideal yang dipilih untuk mendapatkan pelajaran bagaimana seharusnya orang Kristen bermisi. Respon yang bertentangan dengan panggilan sebagai hamba Tuhan menjadi kajian yang menarik untuk mengetahui latar belakang yang membentuk sikapnya. Prinsip-prinsip yang dipaparkan dalam penulisan ini membawa pada kondisi yang paradoksal antara idealisme bermisi dengan keadaan di lapangan. Melalui prinsip hermeneutika, khususnya analisa kesusateraan, analisa latar belakang, analisa redaksi, analisa konteks dan teologis, dicoba dipakai untuk mencari jawaban atas masalah pada sikap Yunus yang bertolak belakang dari tugasnya sebagai Nabi Allah. Termuan akhir dari tulisan ini adalah pada semakin kokohnya eksistensi Allah sebagai Allah yang memberi kesempatan bagi manusia yang bertobat, yang diwujudkan dalam pengampunan, penerimaan, pembatalan akan hukuman, dan pemulihan hubungan dengan manusia. Prinsip praktis yang ditarik dari pembahasan menjadi standar bagaimana orang Kristen seharusnya merespon melalui ketundukan pada otoritas Allah.
\end{abstract}

Kata Kunci : Yunus; misi; missioner; kasih; hukuman; Niniwe 


\section{PENDAHULUAN}

Sebagai seorang nabi Allah, Yunus seharusnya bertindak selaras dengan perintah Allah, namun sikap yang ditunjukkan ketika mendapat perintah untuk "menobatkan" penduduk Niniwe "seakanakan" adalah suatu perlawanan terhadap Allah. Inilah yang akan menjadi issue utama yang akan dibahas dalam paper. Apa yang melatar belakangi seorang Nabi Allah bersikap demikian? Sebagaimana seharusnya seorang Nabi pada zaman Perjanjian Lama memiliki misi menjadi "corong" Allah untuk menyuarakan pertobatan, mengapa jiwa misioner itu tidak terlihat dalam diri seorang Yunus?

Yunus merupakan nabi Allah yang cukup kontroversial berhubung dengan langkah-langkah yang diambil yang terkesan menjauhi perintah Allah. Secara spesifik, kitab Yunus merupakan sebuah kisah tentang sebuah peradaban manusia yang diwakilkan oleh penduduk Niniwe., dan tanggapan Allah yang mewakili karakterNya yang khusus. Secara khusus, Hilton dan Walton menyatakan bahwa kitab ini mengetengahkan hak dan kedaulatan Allah untuk menguraikan tindakan belas kasihan Allah kepada siapapun yang dikehendakiNya. Allah senang untuk menanggapi langkah-langkah kecil kearah yang benar dengan menyatakan tindakan - tindakan kebajikan berupa belas kasihan ${ }^{1}$.

Dinamika cerita yang ditulis dalam kitab Yunus membuka mata pembaca akan sebuah kontras, antara sikap Allah yang konsisten dan Yunus yang terlihat sulit berkomitmen. Issue yang disorot mengenai kenabiannya yang tidak membawa ketaatan membawa pada masalah yang lebih mendasar, yaitu jiwa missionernya yang patut dipertanyakan. Namun sesuatu yang menyejukkan dapat ditemui melalui fakta bahwa dalam menjalankan misi-Nya, Allah juga memberikan pengajaran bahwa penyesalan (manusia) dapat mengalahkan hukuman (Allah), sebagaimana yang dinyatakan oleh Kaufman. ${ }^{2}$

Ada beberapa paper jurnal sejenis yang mengupas tentang tokoh Yunus, namun setiap naskah tersebut memiliki penekanakan yang berbeda, misalnya "Kajian dan Uraian Apologetis Teologis Terhadap Ungkapan ALLAH MENYESAL Dalam Alkitab" yang ditulis oleh Bambang Wiku Hermanto mengambil Kitab Yunus sebagai salah satu contoh kasus yang dipakai untuk menggambarkan sifat Allah yang

${ }^{1}$ Andrew E. Hill \& Joh. H. Wilton, Survey Perjanjian Lama (Malang: Gandum Mas, 2013).

${ }^{2}$ George A. Barton, The Religion of Israel, The Religion of Israel (Chicago: University of Chicago, 2016). 
kasih. $^{3}$ Naskah lainnya ditulis oleh penulis yang sama dengan tajuk Menyingkap Fakta dan Peristiwa Dibalik Tanda Nabi Yunus, menekankan kisah Yunus dari sisi peristiwa 3 hari tiga malam di perut ikan, yang menjadi penanda kematian dan kebangkitan Kristus. ${ }^{4}$ Paper lainnya ditulis oleh Michael Jonathan Sulistiawan dalam artikel jurnal berjudul Makna 'Ketetapan Tuhan’ dalam Kitab Yunus dan Implikasi dalam Pelayanan Kristiani, yang memberikan penekanan lebih besar pada sifat Allah yang kasih, yang membawa Niniwe pada keluputan. ${ }^{5}$ Dan terakhir, Yimmy Iskandar menulis paper berjudul Makna Teologis Respon Nabi Yunus Terhadap Panggilan Tuhan. Memakai pendekatan hermenetik derkriptif, paper ini mengupas tentang karakter Allah dan respon Yunus terhadap panggilan dipandang dari sisi teologis. Berbeda dengan penulis-penulis terdahulu, pembahasan dalam yang ditulis penulis saat ini adalah menggali lebih dalam karakter moral Yunus sebagai seorang nabi Allah, hal-hal yang melatar belakangi ditinjau

\footnotetext{
3 Bambang Wiku Hermanto, "Kajian dan Uraian Apologetis Teologis Terhadap Ungkapan 'Allah Menyesal' dalam Alkitab," Evangelikal: Jurnal Teologi Injili dan Pembinaan Warga Jemaat I 1 (2017).

${ }^{4}$ Seri Damarwanti, "Menyingkap Fakta Dan Peristiwa Dibalik Tanda Nabi Yunus," Sanctum Domine: Jurnal Teologi VII No.1 (2018): 138,

5 Michael Johan Sulistiawan, "Makna 'KetetapanTuhan' Dalam Kitab Yunus Dan Implikasi Dalam Pelayanan Kristiani," Sundermann I No 32 (2020).
}

dari sisi latar belakang sejarah, sosial, karakter dan teologis. Pendekatan yang dipakai memakai hermenetik deskriptif melalui berbagai analisa : analisa teks, sumber, kesusasteraan, sejarah, sosial, moral dan teologis, sehingga didapat gambaran yang utuh dan dalam terhadap jiwa misioner Yusuf yang sejak awal menjadi pertanyaan penelitian.

Pembahasan dalam paper ini dimulai dari masalah mendasar mengenai sikap Yunus yang menentang perintah Allah, yang berlawanan dengan karakter sebagai seorang misioner yang seharusnya. Kemarahan Yunus atas kasih karunia Allah yang membatalkan murka-Nya atas Niniwe membuat nabi ini seolah-olah tidak memiliki visi yang sama dengan Allah. Fenomena ini menimbulkan issue baru : apakah keengganan Yunus melaksanakan misi Allah untuk Niniwe membuat dia menjadi seorang nabi yang tidak missioner ? Bila anggapan awal ini benar, maka pembahasan penelitian ini ada pada usaha untuk menjawab pertanyaan: dalam hal apa terdapat kesenjangan visi antara Yunus dan Allah? Bagaimana seorang Nabi tidak memiliki jiwa missioner? 


\section{METODOLOGI PENELITIAN}

Proses analisa untuk menjawab masalah tersebut secara deskriptif melalui metode hermeneutik dengan pendekatan pada analisa teks, terutama pada bagian perintah Allah yang pertama dan respon Yunus, juga perintah Allah yang kedua dan bagaimana respon Yunus sesudahnya. Kemudian, analisa sumber atau analisa kesusateraan dipakai untuk memberikan gambaran yang lebih detil tentang Kitab Yunus, menyangkut penulis, waktu penulisan, gaya penulisan, lingkungan dan keadaan yang membentuk kitab pada masa tersebut. ${ }^{6}$

Pendekatan pada metodeilmusosial juga diperlukan untuk mendapatkan gambaran mengenai struktursosial yang berlaku pada masa Nabi Yunus. Beyer secara spesifik merekomendasikan hal ini sebagai sebuah pendekatan untuk melihat bagaimana latar belakang keluarga, perang, pemerintahan menjadi sebuah rekonstruksi sosial yang membantu proses penafsiran. ${ }^{7}$

Yang terakhir adalah analisa teologis yang akan dipakai untuk mengetahui

${ }^{6}$ Hasan Sutanto, Hermeneutik. Prinsip Dan MetodePenafsiranAlkitab. XII. (Malang: Literatur SAAT, 2015), 208.

7 Ulrich Beyer, Metode Penafsiran Alkitab XI (Jakarta: BPK Gunung Mulia, 2004), 66. pandangan Allah sendiri mengenai hubungan-Nya dengan manusia dalam kasus ini, melihat implikasi-implikasinya dalam bagian nats yang dipelajari dan apa maknanya bagi umat saat itu dan di masa kini.

Pemaparan mengenai deskrisi kitab Yunus, latar belakang kehidupan tokoh secaras ingkat, deskripsi demografi tentang Niniwe, alur kisah yang dipaparkan dalam kitab dan melalui beberapa ayat kunci yang dipilih untuk digali lebih jauh, dan analisa teologis yang dipakai diharapkan akan didapat fakta dibalik tindakan Yunus, adalah sebuah metode dan pendekatan yang dipilih untuk mendapatkan jawaban yang komprehensif atas pertanyaan penelitian.

\section{ISI DAN PEMBAHASAN}

\section{Deskripsi Kitab}

Hill dan Walton menuliskan bahwa Kitab Yunus merupakan kitab misi. Hal ini disebabkan bahwa dalam kitab ini, Allah mendorong orang Israel (Yunus) untuk melangkah melampaui sifat eksklusif teologisnya, menjangkau bangsa-bangsa lain. Pesan dari kitab Yunu adalah pada kedaulatan Allah yang memberikan belas kasihan-Nya kepada siapapun yang 
dikehendaki-Nya. Tema belas kasihan, kemarahan dan teodesi menjadi nuansa yang kha sdalam kitab Yunus ${ }^{8}$

Kaiser menambahkan bahwa nilai teologis pada kitab Yunus menitik beratkan pada perluasan kasih Allah pada bangsabangsa non-Yahudi. ${ }^{9}$ Sebenarnya, tema ini bukanlah tema yang baru dalam pandangan Allah. Sebelum Yunus, sudah ada orangorang non Yahudi yang disentuh oleh rencana keselamatan Allah, misalnya Rahab, Rut, Yitro. Bullock mengidentifikasi kitab ini dalam kategori Kitab Sejarah. Hal ini mengacu pada ${ }^{10}$ dipakainya bagian dari kisah ini oleh Yesus di Matius 12:39-41 dan Lukas 11: 29-31. ${ }^{11}$ Dapat ditambahkan data bahwa kisah dalam kitab Yunus merupakan fakta sejarah adalah berdasarkan kesamaan bentuk narasi dengan kisah Elia dan Elisa, pun melalui II Raja-Raja 14:25 yang mengenali dia sebagai anak Amitai.

Sebagian penulis berpendapat bahwa Yunuslah yang menulis kitab ini. Namun sebagian lagi menulis tidak diketahui siapa penulis kitab ini sesungguhnya. Kitab ini

\footnotetext{
${ }^{8}$ Andrew E. Hill \& Joh. H. Wilton, Survey Perjanjian Lama.

${ }^{9}$ Walter C Kaiser, Teologi Perjanjian Lama $V$ (Malang: Gandum Mas, 2020), 255.

${ }^{10}$ Kaiser, Teologi Perjanjian Lama V.

${ }^{11}$ Ibid.
}

ditulis dengan kata ganti orang ketiga. Jadi bisa Yunus sendiri, atau orang lain yang sudah mendengarkan ceritanya. Siapa pun yang menuliskan, ia adalah penulis yang sangat mahir. Bahasa Ibraninya lancar dan sederhana, dan kemampuannya menuliskan sebuah cerita tidak terlampaui oleh penulis lain dalam Perjanjian Lama. $^{12}$. Kisahiniterjadisekitartahunke $-8 \mathrm{SM}^{13}$. C Hassel Bullock mencatat bahwa ini terjadi pada masa pemerintahan Raja Yerobeam tahun 793/92 - $753 \mathrm{SM}^{14}$

Tema utama dalam Kitab Yunus antara lain : belas kasihan Allah, murka Allah, Teodisme (membenarkan cara-cara Allah) ${ }^{15}$. Selain itu dapat ditulis : nubuatan yang tidak digenapi (janji Allah melalui Yunus tidak pernah dilaksanakan (Yunus 3:10) - walaupun Allah tidak dapat dipermaikan. Dalam Yunus 3:9 Ia menanggapi pertobatan manusia dan menggenapi maksudnya dengan berbagai cara.

12 C. Hasel Bullock, Kitab Nabi-Nabi Perjanjian Lama (Malang: Gandum Mas, 2009), 69.

13 Marthin Steven Lumingkewas, Teologi Perjanjian Lama 2 (Jakarta: BPK Gunung Mulia, 2020).

Lama.

${ }^{14}$ Bullock, Kitab Nabi-Nabi Perjanjian 15 Ibid. 


\section{Tentang Tokoh}

Beberapa informasi pribadi yang diketahui tentang Yunus, baik melalui Yunus 1:1 maupun melalui II Raja-Raja 14:25 yang mengenali dia sebagai anak Amitai. Kitab Raja-Raja memberikan penjelasan lebih lanjut bahwa ia berasal dari Gat-Hefer, sebuah kota kecil di bagian bawah Galilea, 3 mil sebelah timur Nazaret, di daerah suku Zebulon. Nama Yunus berarti "merpati" suatu kata yang kemudian menjadi lambang Israel $^{16}$. Walton menuliskan bahwa Yunus hidup diperkirakan pada abad ke-8 SM ${ }^{17} 2$ Rajaraja 14:25 mencatat Yunus sebagai seorang Nabi, hamba Allah ${ }^{18}$, seorang nabi Ibrani yang diutus untuk berkhotbah ke Niniwe pada zaman Raja Yerobeam II. Yunus merupakan nabi Ibrani pertama yang diutus ke suatu negeri kafir. ${ }^{19}$

Bullock mencatat bahwa Yunus merupakan nabi yang hidup pada masa peralihan karena ia mewakili perpindahan dari nabi pra - klasik (Nabi Elia dan Nabi Elisa) kepada zaman klasik (Nabi Amos, Hosea, Mikha dan Yesaya). Nabi pra -

\footnotetext{
${ }^{16}$ Ibid.

${ }^{17}$ Andrew E. Hill \& Joh. H. Wilton, Survey Perjanjian Lama.

${ }^{18}$ Konkordansi Alkitab. III. (Jakarta: BPK Gunung Mulia, 1986).

19 JI Packer, Ensiklopedi Fakta Alkitab 2, III. (Malang: Gandum Mas, 2014), 1436.
}

klasik menyampaikan pesannya kepada rajaraja dan istananya sedangkan nabi-nabi klasik menyampaikan pesannya kepada semua lapisan masyarakat. ${ }^{20}$

\section{Tentang Niniwe}

Niniwe merupakan ibu kota kerajaan Asyur, yang terletak di timur sungai Tigris, di wilayah sebelah utara tempat pertemuan antara sungai Tigris dan hulu sungai Zab. ${ }^{21}$ Kota ini mempunyai luas yang luar biasa, yaitu 3 hari perjalanan luasnya. Besaran ini bisa dipandang berdasarkan besarnya tugas dan lamanya tinggal menetap daripada dengan keliling atau diameter sebenarnya kota tersebut. Namun Wiseman menuliskan bahwa menurut penggalian A.H Layard di lokasi Niniwe pada tahun 1843, Layard menyatakan bahwa Niniwe adlaah daerah yang jauh lebih kecil. Perhatian dilakukan kepada lingkaran tembok-tembok yang telah diperbesar oleh Sanherib dari 9.300 kubik ke 12.515, yang memberikan jarak sekitar 7,5 mil. ${ }^{22}$ Populasi penduduknya sekitar 12.000 orang. ${ }^{23}$ Kota ini didirikan oleh

20 Bullock, Kitab Nabi-Nabi Perjanjian Lama.

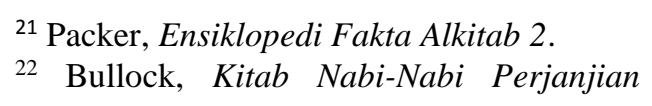

22 Bullock, Kitab Nabi-Nabi Perjanjian Lama.

23 Donald J. Wiseman, Jonah's Niniveh, 1979. 
Nimrod (Kejadian 10 :11) dan merupakan ibu kota Asyur.

Kota ini dinamai kota pertumpahan darah, besar, kaya, kuat perdagannya ramai, penduduknya banyak (Nahum 3). Karakter penduduk kota ini ialah jahat (Yunus 1:2), penyembah berhala (Nahum 1:14), penuh keramaian tapi penduduknya santai (Zef 2:15), penuh dengan dusta dan perampasan (Nahum 3:1), penuh persundalan (Nahum 3:4). Kejatuhannya sudah dinubuatkan oleh Nahum dan Zefanya (612 SM), akibat air sungai yang bendungannya bobol (Nahum 2 :6-8).

\section{Perintah Allah dan Tanggapan Yunus}

Perintah Allah Pertama (1:1-17)

Dalam Yunus 1:1-17, Allah memberikan perintahNya yang pertama kepadaYunus. : “. . . bangunlah (quwm), pergilah keNiniwe . . berserulah (qara'). . .. Jadi Allah memerintahkan Yunus untuk segera bergegas ke Niniwe, untuk memberitakan tentang Allah kepada seluruh penduduk Niniwe. Kata yang dipakai untuk menyatakan apa yang harus dilakukan Yunus di Niniwe adalah qara' yang merujuk pada arti pemberitaan secara terbuka untuk seluruh khalayak Niniwe. Memberitakan Allah dengan suara lantang agar seluruh penduduk Niniwe tahu bahwa Allah telah mengetahui perbuatan jahat penduduk dan bertobat kepada Allah. Allah memperhatikan kelakuan penduduk Niniwe dan menganggap perilaku dan kehidupan Niniwe sebagai sesuatu pelanggaran yang sangat serius.

Tanggapan Yunus terhadap perintah itu adalah : Ia bersiap melarikan diri (barach) ke Tarsis, jauh dari hadapan Tuhan dan Ia membayar sendiri harga dari perjalanan itu. Kata barach berarti pelarian itu dilakukan secara tergesa-gesa, tanpa perhitungan atau pertimbangan yang matang. Dalam kapasitasnya sebagai seorang nabi Allah, tanggapan seperti itu adalah diluar dugaan. Alih-alih melaksanakan perintah, Yunus justru merencanakan pelarian senyap agar tidak perlu melaksanakan perintah Allah.

Yunus mengambil keputusan sendiri, pergi ke arah yang berlawanan agar semakin menjauhi lokasi target, ke Tarsus (Spanyol) yang jaraknya lebih jauh.

Reaksi Allah terhadap sikap Yunus adalah menurunkan angin ribut ke laut, membuat badai besar sehingga kapal yang dinaiki Yunus hampir terpukul hancur. 
Melalui peristiwaini, Yunus dipermalukan karena ketahuan sebagai sumber masalah dan ia dicampakkan ke dalam laut, ia ditelan oleh ikan besar dan tinggal dalam perutnya 3 hari 3 malam lamanya. Yunus membayar sendiri biaya serta kerepotan dari perjalanan itu. Semua hal tunduk kepada kendali kuasa Allah : angin, badai, gelombang, ikan besar. Hanya Yunus yang menentang kehendak Allah. Di samping itu, Yunus harus menanggung malu karena dari hasil undi, ia dianggap sebagai sumber malapetaka di kapal itu. Secara terang-terangan Yunus mengakui identitas diri yang sebenarnya, yaitu seorang Ibrani. Secara tidak sungkan juga menyatakan bahwa ia seorang yang takut akan Allah, tapi tidak ada penyesalan sama sekali dalam perkataannya, justru penumpang lain yang mengakui kemahakuasaan Allah dan menjadi percaya, kemudian memberikan korban kepada Allah.

Waktu kritis dalam peristiwa ini adalah ketika Yunus berada dalam perut ikan, di tengah kegelapan dunia yang asing, di tempat yang tidak terduga dan tersembunyi dari dunia, justru Yunus mengalami rekonsiliasi hubungannya dengan Allah. Situasi ini membawa pada kenyataan bahwa tidak ada tempat untuk bersembunyi dari Allah. Eksistensinya yang
Maha Hadir membawa Yunus pada pemahaman yang semakin dalam tentang kuasa dan karakter Allah. Yunus terhenyak dan sadar bahwa kasih Allah tidak eksklusif hanya kepada umat Israel, tetapi juga kepada bangsa-bangsa lain di seluruh dunia. Kasih karunia-Nya melampaui identitasbangsa, ruang dan waktu. Siapakah Yunus, sehingga berencana untuk menyangkali keagungan pribadi Allah yang Maha Kasih dan pergi lenyap agar Allah tidak memakai dirinya sebagai alat-Nya? Siapakah Yunus sehingga berpikir bahwa seseorang dapat menggagalkan rencana Allah untuk keselamatan manusia?

Virkler mencatat secara khusus dan memaklumi sikap antipati Yunus kepada Niniwe adalah karena Asyur pada masa itu adalah sebuah kekuatan besar dan menjadi musuh bagi Israel, jadi dalam konteks inilah perintah Allah datang kepada Yunus. Ditambahkan lagi, pertobatan Niniwe bisa jadi merupakan hal yang menakutkan bagi Yunus, yang mengetahui bahwa pesan dari Allah itu bersyarat. Bia Yunus dapat meghindari pesan Allah sampai kepada penduduk Niniwe, maka pertobatan Niniwe akan dapat dicegah, sehingga malapetaka akan datang menimpa Niniwe. Itu bukan hal 
yang diharapkan Yunus, oleh karena faktor historis antara Asyur dan Israel. ${ }^{24}$

Jadi, dari fakta - fakta di bagian perintah Allah yang pertama membawa pada pemahaman dan realitas bahwa kelas kerohanian dan karakter seorang nabi, hamba Allah, masih perlu berproses, dibentuk melalui peristiwa-peristiwa yang menyakitkan dan tidak diharapkan, yang membawa pada kedewasaan. Kedewasaan atas karakter, kesadaran yang lebih matang pada amanah Ilahi yang bekerja melaluinya, dan kematangan emosi dan visi untuk taat di bawah kedaulatan dan otoritas Allah di setiap segi kehidupan. Dalam bagian ini Yunus bukanlah model yang ideal. Tetapi Yunus akhirnya "menyerah" dan tunduk. Bagian ini menjadi point penting dalam menjawab pertanyaan di awal.

Perintah Allah Kedua (3:1-10)

Dalam Yunus 3:1-10 dituliskan perintah Allah selanjutnya kepada Yunus: “. . . Bangunlah, pergilah keNiniwe, dan sampaikanlah (qara') kepadanya ... . “. Perintah Allah yang kedua memakai istilah yang sama dengan perintah yang pertama :

${ }^{24}$ Henry A Virkler, Hermeneutik PrinsipPrinsip Dan Proses Interpretasi Alkitab V (Yogayakrta: Andi Offset, 2019), 185. qara', pergi untuk memberitakan berita yang sama, dengan cara yang sama, kepada populasi yang sama. Jadi Allah tidak merubah esensi dari tujuan dan maksud Yunus ke Niniwe, baik dalam perintah-Nya yang pertama maupun kedua.

Yang berbeda dari tanggapan Yunus yang kedua adalah : "bersiaplah Yunus dan pergi ke Niniwe, sesuai dengan firman Allah". Hasilnya : orang Niniwe percaya. Kata yang dipakai dalam ayat ini untuk menyatakan respon orang Niniwe adalah 'aman yang artinya: believe, assurance, faithfull...kepada Allah. Respon berikutnya dari orang Niniwe adalah berpuasa dan berkabung, . . . berbalik dari tingkah lakunya, (shuwb) yang jahat dan dari kekerasan yang dilakukannya. Kata shuwb merujuk pada suatu arti berbalik dari perbuatan yang lama, memperbaiki sikap dan prilaku yang bertolak belakang dari sikap semula. Reaksi Allah terhadap hal itu adalah: ... menyesallah (nacham) Allah rasa sesal yang mengandung makna hati yang berubah menjadi penuh belas kasihan karena malapetaka yang sudah dirancangkannya (asah') dan Ia pun tidak jadi atau mengurungkan niat-Nya yang semula. Melalui bagian ini dipelajari betapa dalam kasih dan belas kasihan Allah bagi 
manusia, yang mendasari setiap keputusan yang dilakukan-Nya pada Niniwe, dan bagi dunia ini secara keseluruhan.

Pengalaman pahit dalam penolakan panggilannya yang pertama membuat Yunus memberikan respon yang berbeda ketika Allah memanggil dia untuk ke Niniwe lagi. Kali ini Yunus segera bergegas ke Niniwe dan memperkatakan nubuatan yang dari Allah. Hasilnya, orang Niniwe percaya kepada Allah. Raja Niniwe pun mempermaklumkan puasa dan masa berkabung agar murka Allah tidak jadi menimpa Niniwe. Tidak hanya manusia, namun juga hewan menjalani masa puasa, merendahkan diri dan prihatin. Raja mempermaklumkan agar setiap orang Niniwe berbalik dan menyesali dosadosanya. Dan memang setiap orang Niniwe berbalik dan bertobat dari dosa-dosa mereka. Tujuannya hanya satu : agar murka Allah tidak menimpa Niniwe. Siapa tahu, Allah mengubah ketetapannya. Dan hasilnya, Allah tidak jadi (membatalkan) hukumanNya atas Niniwe.

\section{Beberapa kisah dalam Perjanjian}

Lama menolong dalam memberikan gambaran mengenai sifat Allah yang penuh belas kasihan, tidak jarang Ia menyesali apa yang sudah dirancangkan-Nya, kepada umat-Nya untuk memberi mereka pelajaran
- pelajara iman. Hal ini dipandang sebagai sebuah kesempatan bagi Raja untuk melakukan segala sesuatu guna mendapatkan belas kasihan Allah.

Respon yang aneh yang ditemukan adalah adanya ekspresi kemarahan Yunus melihat Allah membatalkan murka-Nya atas Niniwe sebagaimana yang terekam dalam Yunus $4: 1$ - 4, yaitu: Di ayat 1 : .. "mengesalkanhati" ( $r a^{\prime} a$ '). Kata yang dipakai dalam mengandung makna rasa kesal dan sebal yang didasarkan atas hati yang jahat. Kata berbuat jahat, Kemudian ... "marahlah" (charah) yang merupakan reaksi marah yang datang secara spontan dan segera. Kemudian di ayat $3: \ldots$ “cabutlah kiranya nyawaku, karena lebih baik aku mati daripada hidup". Perkataan ini adalah luapan kemarahan dan kedongkolan yang amat sangat sehingga Yunus seolah tidak rela menyaksikan belas kasihan dan kemurahan Allah atas Niniwe. Kematian dipandang Yunus sebagai kondisi yang lebih baik daripada harus menyaksikan hal itu. Ayat 5 mempertegas emosi tersebut dengan menyalin bahwa Yunus menantikan apa yang akan terjadi atas kota itu. Kemarahan yang lebih dalam diekspresikan di ayat 8 ketika Yunus melihat pohon jarak tempatnya berteduh pun dimakan ulat, dan sekali menegaskan bahwa kematiannya jauh 
lebih baik daripada mengalami peristiwa tersebut dan ayat 9 dengan penuh kesadaran Yunus berharap kemarahannya membawanya pada kematian (marah sampai mati).

Rasa sesal atas kematian pohon jarak dipakai Allah untuk mendapatkan pengertian Yunus terhadap isi hati Allah melalui ayat 11, “engkau sayang kepada pohon jarak . . . bagaimana tidak aku sayang (chuwc) kepada Niniwe? Kata "sayang" dalam kalimat ini berasal dari kata chuwc yang artinya perasaan kasih yang berasal dari belas kasihan yang dalam. Tentu saja membadingkan perasaan kasih Yunus kepada pohon jarak tidak sebanding dengan kasih Allah kepada manusia yang digambarkan dalam peristiwa Niniwe, tetapi setidaknya Allah dapat memakai peristiwa pohon jarak sebagai dasar pijak untuk membuat Yunus mengerti isi hati Allah.

Beberapa kejanggalan ditemukan sehubungan dengan reaksi Yunus ketika melihat bahwa Allah membatalkan hukuman-Nya atas Niniwe. Hal ini menjadi janggal karena sebagai seorang nabi Allah, tidak sepantasnya Yunus melakukan hal-hal demikian. Kembali kepada persoalan di awal, dalam hal apa terdapat kesenjangan visi antara Yunus dan Allah? Bagaimana seorang Nabi tidak memiliki jiwa missioner? Pertama, secara historis sebagaimana yang telah dipaparkan di bagian latar belakang penulisan ini, kemarahan Yunus kepada Allah "mungkin" dapat dianggap cukup mendasar. Pada masa Yunus, Niniwe memiliki reputasi sebagai kota yang penduduknya banyak melakukan hal-hal yang jahat dalam pandangan Allah. Kaiser menggambarkan bahwa Asyur merupakan tetangga di luar bangsa Israel yang bersifat paling bermusuhan dan agresif. ${ }^{25}$ Tentara Asyur merupakan tantara dengan kekejian yang amat sangat sebagaimana yang terekam dalam Nahum pasal 2 dan 3. Nahum mendeskripsikan secara detil apa yang membangun reputasi militer Asyur yang menimbulkan kengerian dan kegentaran bagi seluruh kerajaan di sekitarnya pada masa itu. Keengganan Yunus pergi ke Niniwe terjadi karena persepsi yang buruk tentang Niniwe membuat gentar dan takut. Alasan ini membuat Yunus lari menjauhi Niniwe dan pergi ke Tarsus. Lebih baik menolak perintah Allah daripada mentaati-Nya tetapi harus pergi ke Niniwe. Sekalipun Yunus

25 Bullock, Kitab Nabi-Nabi Perjanjian Lama. 
adalah nabi Allah, rasa takut dan gentar sehingga lari dari panggilan adalah fakta yang tidak dapat dipungkiri. Ketakutan yang mendominasi dan menyingkirkan ketaatan kepada Allah.

Kedua, masih dalam perspektif historis, sesuai dengan yang tercatat dalam 2 Tawarikh 28:12-26 dituliskan tentang kerjasama Raja Ahas dengan kerajaan Asyur yang berujung pada semakin dalamnya kerajaan Yehuda terjerembab dalam penyembahan berhala dan dikuras habis oleh Asyur sedikit banyak menumbuhkan jiwa nasionalis Yunus memberontak. Kecintaan pada bangsanya menambah keengganannya pergi ke Niniwe. Terdapat solidaritas dan jiwa kebangsaan yang kuat yang menjadi sumber pembalasan yang dilampiaskan melalui rencana untuk "membatasi" belas kasihan Allah kepada penduduk Niniwe. Menganggap bahwa Asyur, Niniwe seharusnya merupakan perkecualian dari belas kasihan Allah.

Ketiga, penyembahan berhala, kemalasan, percabulan, sundal dan sihir serta materialistis adalahdosa-dosa yang seharusnya menjadi alasanAllah menghukum Niniwe, ditambah lagi dengan pandangan Yunus bahwa penduduk Niniwe bukanlah umat pilihan Allah. Tidak ada alasan bagi Allah merasa sayang dan memberikan belas kasihan kepada Niniwe. Hal inilah yang membuat Yunus marah dan segera meninggalkan kota itu. Sambil memandang dan duduk dari kejauhan, ia sungguh berharap murka dan pembalasan Allah menimpa kota itu.

Namun Allah memberikan 2 kali teguran : "pantaskah engkau marah?". Pertanyaan Allah menolong Yunus menyadari eksistensi dirinya dan eksistensi Allah. Bukankah Yunus "hanya" seorang hamba, yang seharusnya menjalankan perintah tuannya? Seorang hamba yang seharusnya dapat memiliki visi tuannya dan bergerak selaras dengan visi itu.

Menilik peran nabi pada zaman Perjanjian Lama, seorang nabi Allah harus memiliki watak yang khusus. Dryness menuliskan bahwa Nabi adalah orang yang berpengalaman pribadi dengan Allah, yang memberikan kepada mereka kesadaran baru dan hidup mengenai keadilan dan kasih Allah. ${ }^{26}$ Jadi seorang nabi Allah dituntut memiliki karakter moral yang sejalan dengan karakter moral Allah : menegakkan keadilan dan kasih. Dalam Yunus, karakter kasih tersebut mengundang keraguan, karena dalam Yesaya $6: 5$, Yesaya sebagai

26 William Dryness, Tema - Tema Dalam Teologi Perjanjian Lama IX, ed. Bertha Gasperz (Malang: Gandum Mas, 2020), 194-195. 
nabi Allah mengatakan bahwa ia yang selama ini tinggal di tengah-tengah bangsa yang najis bibir, matanya telah melihat Sang Raja, Tuhan semesta alam. Penglihatan dan pengalamannya bersama-sama Yang Kudus membuat hatinya sedih akan dosa-dosa umat. Demikian pula dengan Natan ketika menuding Daud setelah perzinahannya dengan Batsyeba di 2 Samuel 12:7. Perjumpaan dengan Allah yang adil dan kasih seharusnya membawa Yunus juga, pada kelantangannya pada perbuatan dosa. Dalam hal ini penduduk Niniwe, namun kualifikasi karakter moral tersebut tidak ditemukan pada Yunus.

Melalui pembahasan sebelumnya, Yunus bukannya tidak mengerti atau tidak memiliki visi missioner, tetapi visi itu menjadi kabur ketika berhadapan dengan konflik internal masa lalu, menjadi tidak jelas ketika berhadapan dengan emosi dan perasaan gentar. Visi dan misi dapat menjadi kalah penting dibandingkan dengan ketaatan kepada Allah dan belas kasihan kepada yang belum mendengar kabar keselamatan. Ketidakrelaan sesuatu yang baik terjadi pada suatu bangsa karena kepahitan yang terjadi di masa lalu membuat suara kenabian Yunus menjadi tumpul. Yunus memilih - milih bangsa yang akan diberitakan kabar baik, dimana Allah sendiri tidak pernah melakukan pemilihan.

Jadi, sesuatu yang menyejukkan dapat ditemui melalui fakta bahwa dalam menjalankan misi-Nya, Allah juga memberikan pengajaran bahwa penyesalan (manusia) dapat mengalahkan hukuman (Allah), sebagaimana yang dinyatakan oleh Kaufman. ${ }^{27}$ Melalui bagian dari perintah Allah yang pertama, Allah menegaskan eksistensi dan posisinya bahwa Ia adalah Allah yang berdaulat dan berotoritas, kepada umat manusia, dan Yunus tentunya, secara spesifik. Memperkokoh posisi Yunus sebagai Nabi yang perlu menyamakan visinya dengan visi Allah. Misinya dengan misi Allah. Sebagai seorang hamba Allah, Yunus perlu mengakselesrasi kedua hal ini sehingg maksud dan tujuan Allah bagi dunia terpenuhi melalui Yunus.

\section{KESIMPULAN}

Sebagai seorang Nabi Allah, Yunus belajar untuk menyamakan visinya dengan visi Allah. Tujuannya dengan tujuan Allah. Orientasi Allah pada dunia adalah pada jiwa. Yunus pun hendaknya demikian. Yunus bukannya tidak memiliki visi dan bukannya 
tidak berjiwa missioner, namun visi dan misi Yunus masih terbatas pada kepentingan kaum dan bangsanya. Ia harus mengembangkan pemahamannya sesuai dengan pemahaman Allah bahwa keselamatan disediakan Allah bagi semua orang di semua belahan dunia, bukan hanya untuk bangsa Israel saja.

Orang Kristen perlu melakukan akselerasi visi dan misi Allah dalam kehidupan. Seorang Kristen perlu menghilangkan rintangan yang menghalangi visi dan misi Allah bagi dunia agar dapat menjadi misi yang efektif, melalui menyamakan persepsi, tujuan, sikap hati dan emosi agar sesuai dengan tujuan dan isi hati Allah. Melalui kisah Yunus, orang Kristen belajar bahwa Allah mengasihi setiap orang dan merobohkan batas-batas perbedaan yang dibuat oleh ras, sejarah dan kebangsaan. Pertobatan manusia membatalkan hukuman Allah. Akhirnya, temuan mengenai visi dan misi Allah secara khusus dalam konteks Kitab Yunus membawa pada pemahaman yang lebih dalam tentang karakter Allah, dasar keputusan-Nya dan bagaimana orang Kristen masa kini mendapatkan pelajaran berharga tentang bagaimana bermisi di zaman modern.

Secara praktis, penulisan paper ini menggiring orang Kristen pada beberapa fakta penting, antara lain : pertama, dalam keunikannya sebagai manusia, Allah dapat memakai siapa saja untuk menggenapi dan menjalankan rencana-Nya bagi dunia. Banyak figur dalamAlkitab yang tidak sempurna, masih bergumul dalam keinginan diri sendiri, yang terang-terangan dipakai Allah untuk pekerjaan-Nya. Yunus pun demikian. Setiap hamba Allah di masa kini, seraya melakukan pekerjaan di ladang misi, masih perlu diperbaharui dan dibentuk dari sehari ke sehari, dari peristiwa demi peristiwa, menuju pada kehidupan yang semakin berkenan kepada Allah.

Dan yang ketiga adalah mengembangkan kepekaan akan kebutuhan orang-orang di sekitar, untuk kemudian mencari jalan bagaimana menjangkau mereka bagi Kristus. Dalam sejarah gereja mula-mula Allah memakai setiap orang yang mewakili seluruh lapisan dan strata, gender, profesi, talenta dan kepandaian untuk menjadi alat-Nya bagi pertumbuhan gereja. Melintasi segala zaman, prinsip ini masih berlaku di zaman sekarang. Di tengah tekanan arus globalisasi, modernisasi, kehidupan di dunia nyata dan maya, masih dibutuhkan hati yang melihat dunia dengan belas kasihan dan kasih pada Allah. Semoga pembaca tidak menjadi seperti Yunus di panggilannya yang pertama, namun dapat 
bergegas dan pergi kemana Allah memerlukan, dan bukan melarikan diri.

\section{DAFTAR PUSTAKA}

Andrew E. Hill \& Joh. H. Wilton. Survey Perjanjian Lama. Malang: Gandum Mas, 2013.

Barton, George A. The Religion of Israel. The Religion of Israel. Chicago: University of Chicago, 2016.

Beyer, Ulrich. Metode PenafsiranAlkitab XI. Jakarta: BPK Gunung Mulia, 2004.

Bullock, C Hasel. Kitab Nabi-Nabi Perjanjian Lama. Malang: Gandum Mas, 2009.

Damarwanti, Seri. "Menyingkap Fakta Dan PeristiwaDibalik Tanda Nabi Yunus." SANCTUM DOMINE: JURNAL TEOLOGI VII No.1 (2018): 138.

Dryness, William. Tema - Tema Dalam Teologi Perjanjian Lama IX. Edited by Bertha Gasperz. Malang: Gandum Mas, 2020.

Johan Sulistiawan, Michael. "Makna 'KetetapanTuhan' Dalam Kitab Yunus Dan Implikasi Dalam Pelayanan Kristiani.” Sundermann I No 32 (2020).

Kaiser, Walter C. Teologi Perjanjian Lama $V$. Malang: Gandum Mas, 2020.

Lumingkewas, Marthin Steven. Teologi Perjanjian Lama 2. Jakarta: BPK Gunung Mulia, 2020.

Packer, JI. Ensiklopedi Fakta Alkitab 2. III. Malang: Gandum Mas, 2014.
Sutanto, Hasan. Hermeneutik. Prinsip Dan MetodePenafsiranAlkitab. XII. Malang: Literatur SAAT, 2015.

Virkler, Henry A. Hermeneutik PrinsipPrinsip Dan Proses Interpretasi Alkitab V. Yogayakrta: Andi Offset, 2019.

Wiku Hermanto, Bambang. "Kajian dan Uraian Apologetis Teologis Terhadap Ungkapan 'Allah Menyesal' dalam Alkitab.” Evangelikal: Jurnal Teologi Injili dan Pembinaan Warga Jemaat I 1 (2017).

Wiseman, Donald J. Jonah's Niniveh, 1979.

Konkordansi Alkitab. III. Jakarta: BPK Gunung Mulia, 1986. 
100 | SANCTUM DOMINE: Jurnal Teologi, vol. 10, no. 1 (2020) 